\title{
Processo de coordenação e subordinação em um livro didático - um estudo à luz de bakhtin e o círculo
}

\author{
Process of coordination and subordination in a textbook - a study in the light \\ of bakhtin and the circle
}

Ediram de Souza Paixão

Vânia Lúcia Menezes Torga

Universidade Estadual de Santa Cruz - UESC - Ilhéus - Bahia - Brasil

\begin{abstract}
Resumo: O presente artigo de cunho teórico-qualitativo tem como foco principal a reflexão sobre a abordagem de períodos compostos no livro didático - Português: Literatura, gramática e produção de texto vol. 3 (Sarmento; Tufano, 2010) à luz dos estudos bakhtinianos. A questão de pesquisa que nos orienta é: como e se a proposta de estudo do processo de coordenação e subordinação dos períodos compostos no livro didático selecionado pode permitir que os alunos, leitores e produtores de textos em vários gêneros, percebam que as escolhas estilísticas feitas pelos estudantes, por um ou outro período simples ou composto, podem sinalizar múltiplos sentidos, mediados pela linguagem verbal e verbo-visual. Assim, pautada nas contribuições de Bakhtin e do Círculo concernentes às discussões sobre os gêneros discursivos, analisamos no livro didático supracitado o funcionamento dos processos dos períodos compostos nos textos dos gêneros Literários e de Divulgação Científica presentes nele, a fim de responder às questões iniciais suscitadas por esta pesquisa. Portanto, conforme os primeiros estudos e análises, concluiu-se que no referido livro didático há, ainda, o predomínio de uma abordagem centrada no estudo da sintaxe dos períodos compostos como unidades da língua com ênfase na classificação das orações inseridas em textos de diferentes gêneros discursivos, sendo pouco explorada a importância das escolhas estilísticas para a produção de sentido nas práticas discursivas e textuais que sinalizam os múltiplos sentidos para os envolvidos na interação verbal.
\end{abstract}

Palavras-chave: Gêneros discursivos; Subordinação; Coordenação.

\begin{abstract}
The present theoretical-qualitative article has as main focus the reflection on the approach of compound periods in the didactic book - Portuguese: Literature, grammar and text production vol. 3 (Sarmento; Tufano, 2010) in the light of Bakhtinian studies. The research question that guides us is: how and if the proposed study of the process of coordination and subordination of compound periods in selected textbook readers and producers of texts in various genres realize that the stylistic choices made by students, for one or other simple period or compound, can signal multiple meanings, mediated by verbal and verbal-visual language. Thus, based on the contributions of Bakhtin and the Circle concerning the discussions on discursive genres, we analyzed in the textbook mentioned above the functioning of the processes of compound periods in texts of literary genres and of scientific dissemination present in it, in order to answer the questions raised by this research. Therefore, according to the first studies and analyzes, it was concluded that in this textbook there is also the predominance of an approach centered in the study of the syntax of compound periods as units of the language with emphasis on the classification of sentences inserted in texts of different genres discourse, and the importance of stylistic choices for the production of meaning in the discursive and textual practices that signal the multiple senses for those involved in verbal interaction is little explored.
\end{abstract}

Key words: Speech Genre; Subordination; Coordination. 


\section{Introdução}

Pautado nas contribuições de Bakhtin e o Círculo, o presente artigo justifica-se por investigar como e se no livro didático de Língua Portuguesa Português - Literatura, gramática, produção de texto, (Sarmento; Tufano, 2010), o processo de coordenação e subordinação dos períodos compostos pode preparar o estudante para a produção de textos nos variados gêneros, possibilitando-lhe perceber como as escolhas estilísticas feitas no momento da produção textual, por um ou outro período simples ou composto, podem indiciar múltiplos sentidos para os envolvidos na interação verbal.

O livro, corpus da investigação, foi um dos livros aprovados no Programa Nacional do Livro Didático (PNLD, 2012), e passou a ser utilizado em 2013 pelas escolas que o adotaram. Embora o livro esteja dividido em 20 capítulos, subdivididos nas seções de gramática, literatura e produção textual, concentramos nossa análise, para efeito de recorte metodológico, nos capítulos 8 e 9 . O recorte se deu porque nesses capítulos temos gêneros discursivos que exemplificam os que circulam socialmente e que são pouco explorados na sua finalidade, além de enfatizar a abordagem dada à sintaxe dos períodos.

No tocante ao ensino de Língua Portuguesa, embora tenha passado por muitas mudanças ao longo do seu desenvolvimento enquanto componente curricular de ensino, ainda assim, há muitos aspectos que precisam ser melhorados, principalmente no que diz respeito ao processo ensino-aprendizagem de leitura e produção escrita, conforme afirma Brait:

As mudanças nas políticas de ensino, somadas às mudanças nas concepções científico-metodológicas e à sofisticação dos materiais didáticos, especialmente os livros que concorrem hoje aos programas oficiais do governo, não correspondem enquanto volume de investimento público e privado, a índices de melhora na leitura e produção escrita e oral dos alunos (BRAIT, 2013, p.13).

Se diante de tantas transformações ainda não são satisfatórios os efeitos na aprendizagem dos alunos, evidencia-se a necessidade de maiores investimentos de cunho científico e metodológico para alcançar o nível desejado de um ensino que prepare eficazmente o aluno para explorar as habilidades que possui e que devem ser desenvolvidas ao longo da vida escolar. Portanto, como uma possível forma de contribuir com as reflexões sobre o ensino da sintaxe dos períodos compostos, a presente proposta justifica-se por suscitar discussões em torno das questões sobre 0 processo de coordenação e subordinação.

Nesse sentido, o presente artigo traça reflexões sobre a constituição da oração e também dos conceitos de enunciado/enunciação em Bakhtin e - Círculo, e sobre o processo de coordenação e subordinação, mais especificamente a partir do ensaio Mikhail Bakhtin - Questões de estilística no ensino da língua. Por conseguinte, debruçamos nosso olhar na análise do processo de subordinação e coordenação nos gêneros da esfera da Divulgação Científica e gêneros Literários dispostos no livro didático em estudo. Assim, retomamos as principais discussões que evidenciam como o processo dos períodos compostos foi tratado, refletindo como a abordagem inserida nele pode contribuir para que 0 aluno compreenda a importância das escolhas estilísticas para a produção do sentido.

\section{Oração/ Enunciado/Enunciação}

Nos estudos da língua(gem), as discussões voltadas para a maneira como é realizado o processo de produção de textos nos apontam uma certa divergência de conceitos referentes ao que seja frase, oração, enunciado e formação dos períodos compostos. É comum encontrarmos nos livros didáticos ou em outros textos dirigidos a professores e/ou alunos, esses termos sendo utilizados como sinônimos, negligenciando a concepção teórica que fundamenta cada um deles. Entretanto, tomar um pelo outro como se fosse o mesmo vocábulo é reduzir a compreensão dos fenômenos da linguagem, ignorando os diversos marcos teóricos que os sustentam.

Considerando o que é pontuado de maneira consensual na maioria das gramáticas normativas, a 
princípio, é aceitável entender frase como um arcabouço linguístico de sentido completo e que não depende do contexto extralinguístico, discursivo ou ideológico. Quando é estruturada a partir de um verbo, constitui-se como oração. Já o enunciado, seria essa construção linguística (frase/oração) processada dentro de um contexto intra e extralinguístico, visto que faz parte da experiência comunicativa entre os indivíduos.

Para a pesquisa em questão, sustentada na abordagem de Bakhtin e o Círculo, entendemos o enunciado como um elemento da comunicação discursiva, ressaltando que sua existência se dá por meio da interação entre os interlocutores nas diferentes atividades discursivas, portanto, entendese que:

[...] o enunciado não é uma unidade convencional, mas uma unidade real, precisamente delimitada pela alternância dos sujeitos do discurso, a qual termina com a transmissão da palavra ao outro por mais silencioso que seja o "dixi" percebido pelos ouvintes [como sinal] de que 0 falante terminou. (BAKHTIN, 2016, p.29)

De acordo com Bakhtin (2016, p.26), "cada enunciado é um elo na corrente complexamente organizada de outros enunciados" e como tal, possui limites definidos que se dão através da alternância dos sujeitos do discurso. Ou seja, cada enunciado traz consigo as marcas e contribuições de outros enunciados, por isso, diz-se que cada enunciado é uma resposta aos enunciados anteriores e pressupõe enunciados posteriores, mesmo que seja absoluto e acabado num tempo/espaço, são eles que formam o discurso dos sujeitos da enunciação. Em suma, os enunciados se configuram como gêneros discursivos e conforme Bakhtin (2016, p. 20) "são correias de transmissão entre a história da sociedade e a história da linguagem".

Desse modo, compreendemos que 0 enunciado só existe quando há a interação entre os sujeitos e tem a possibilidade de satisfazer, como afirma Bakhtin (2016, p. 23, 24), "ao seu objeto (isto é, ao conteúdo do pensamento enunciado) e ao próprio enunciador". Assim, o enunciado como unidade discursiva é usado pelos falantes para concretizar o desejo de expressar-se por meio da língua, pois, segundo Bakhtin (2017, p.177) "de fato, o objetivo do falante é direcionado a um enunciado concreto pronunciado por ele. Para ele, não se trata da aplicação de uma forma normativa idêntica [...] em um contexto concreto". Apesar disso, nenhum enunciado, desde o mais completo e rico significativamente, constitui uma totalidade num processo da comunicação verbal, conforme pontua Bakhtin (2017, p.219) "é apenas um momento da comunicação discursiva ininterrupta (cotidiana, literária, científica, política, etc.)".

Uma das particularidades fundamentais do enunciado em relação à oração é a possibilidade de ocorrência da alternância entre os sujeitos - parceiros da comunicação, o que pressupõe a necessidade de resposta e o estabelecimento de um começo e finalização de qualquer que seja a situação enunciativa. Bakhtin (2016, p. 61) afirma que "todo enunciado, além do seu objeto, sempre responde (no sentido amplo da palavra) de uma forma ou de outra aos enunciados do outro que o antecederam".

Os aportes teóricos de Bakhtin sobre enunciação apontam que enquanto o enunciado está relacionado às situações reais da comunicação, a oração é uma unidade convencional da língua. Todavia, conforme os estudos bakhtinianos, existem aspectos que podem fazer com que esta unidade linguística se transforme num enunciado pleno, pois ultrapassa o contexto de fala de um mesmo falante.

A oração, parte constitutiva da enunciação, passa a ter uma conotação "semântica especial", sendo assim, Bakhtin (2016, p. 32) esclarece que "em relação a ela pode-se ocupar uma posição responsiva, com ela se pode concordar ou discordar, executá-la, avaliá-la, etc.; ela ganha essa capacidade [...] apenas no conjunto do enunciado". Em consonância, Sobral (2009) esclarece como o Círculo distingue as unidades da língua das unidades discursivas:

O enunciado pode ser definido como uma unidade discursiva mediante a qual o locutor busca realizar um dado projeto enunciativo, de acordo com a interação em que está envolvido (e que o leva a alterar esse projeto enunciativo ao longo de sua execução), tendo por material as formas da língua e imprimindo ao que é dito um tom avaliativo que leva em 
conta a resposta ativa presumida do interlocutor a quem o locutor se dirige. $O$ enunciado é unidade discursiva porque vai além das unidades linguísticas que são a palavra, a frase e o texto como materialidade. $O$ enunciado situa-se entre o verbal e o nãoverbal, serve-lhes de mediador; ele traz o não verbal em sua própria estrutura verbal: o contexto extra-verbal deixa marcas no enunciado nele produzido, e, na verdade, torna-se 'intra-verbal'. O que interessa do contexto está contido no enunciado, porque a enunciação que o produz inscreve nele essas marcas, e são elas que autorizam o analista a buscar elementos contextuais. (SOBRAL, 2009, p. 98)

Nesse sentido, acreditamos na possibilidade e necessidade de estudar os processos de coordenação e subordinação, atentando para uma abordagem dialógica da linguagem pautada nas proposições dos gêneros discursivos, a fim de discutir que as orações, enquanto unidades da língua, são utilizadas na constituição de um estilo para concretizar a materialidade discursiva de um determinado gênero. Em suma, podemos justificar o entendimento das formas dos processos de constituição dos períodos compostos (coordenação e subordinação) com fins, também, estilísticos "porque a própria escolha de uma forma gramatical pelo falante é um ato estilístico." (BAKHTIN, 2016, p.22)

\section{Períodos compostos no manual didático:} português - literatura, gramática, produção de texto - praticando com os gêneros discursivos

Os períodos compostos por coordenação (com ou sem conjunção) podem ser considerados como enunciados, pois, possuem um sujeito enunciador que os produziu, considerando uma situação de interação, mesmo que o interlocutor - o outro - não esteja fisicamente presente e também porque todo material linguístico, ali representado, é dialógico, ou seja, "um fenômeno textual e um procedimento discursivo englobado pelo dialogismo" e possui uma materialidade discursiva, (SOBRAL, 2009, p. 34).

Portanto, o que se espera ao observar o processo de coordenação e subordinação bem como as atividades referentes ao assunto no livro selecionado é a ocorrência ou não de construções que remetem à reflexão dos enunciados como parte das ações humanas, concretizadas a partir do "confronto entre um 'isto' e um 'aquilo', um 'eu' e 'tu'," (SOBRAL, 2009, p. 35). Assim, entendemos que quando o estudo das formas da língua contempla as relações dialógicas, provavelmente, possibilita aos estudantes indagar, refutar, repensar e posicionar-se frente à realidade social.

Ao propor ao aluno que atente para a estruturação interna dos enunciados dos textos lidos, o importante é criar condições para que ele perceba as relações entre os termos desses enunciados, para aprender mais sobre as variadas possibilidades de articulação frasal dos recursos expressivos da língua. (COSTA VAL, 2002, p.123)

Desse modo, a escolha de um texto literário poético e dois textos da Divulgação Científica possibilitou-nos com esse recorte o desenvolvimento de nossas análises. Esse recorte foi feito porque os demais textos e atividades que compõem os capítulos selecionados para a pesquisa são uma mera repetição do que é visto nos anteriores, ainda que contemplem outras orações, mas a linha de análise e constituição das propostas de trabalho são a mesma.

A escolha desses gêneros se deve ao fato de que consideramos que: a) o texto literário tem sido abordado quase tão somente nas aulas de literatura como gênero literário e sendo relegado a segundo plano nas aulas de língua, então, lançamos nosso olhar sobre esse material, compreendendo-o como uma variante linguística que pode e deve ser contemplado, também, nas aulas de língua portuguesa; b) os textos da Divulgação Científica servem apenas de pretexto, mas não têm uma abordagem enunciativa real, no entanto, é importante prepararmos nossos alunos para que ao lerem um artigo num jornal, numa revista tal como a revista Superinteressante ou outra qualquer, ao assistir a um documentário científico ou programa de divulgação de avanços da ciência que ele perceba que há ali, um que fala pelo outro, para o outro e que tal constituição discursiva pressupõe estratégias específicas do gênero. Diante disso, passaremos para nossas considerações sobre o texto literário, poema Lampejo, do escritor Ferreira Gullar, utilizado com fins de explorar a questão das orações coordenadas. 


\section{O período composto por coordenação num gênero literário - sintaxe e estilo}

Tendo como princípio que "a linguagem literária é um sistema dinâmico e complexo de estilos de linguagem; o peso específico desses estilos e sua inter-relação no sistema da linguagem literária estão em mudança permanente" (BAKHTIN, 2016, p.20), destacamos que o poema Lampejo (Figura 1 e 2), torna-se relevante para discutirmos a ocorrência das orações coordenadas em sua constituição estilística.

\section{Figura 1 - Poema Lampejo}

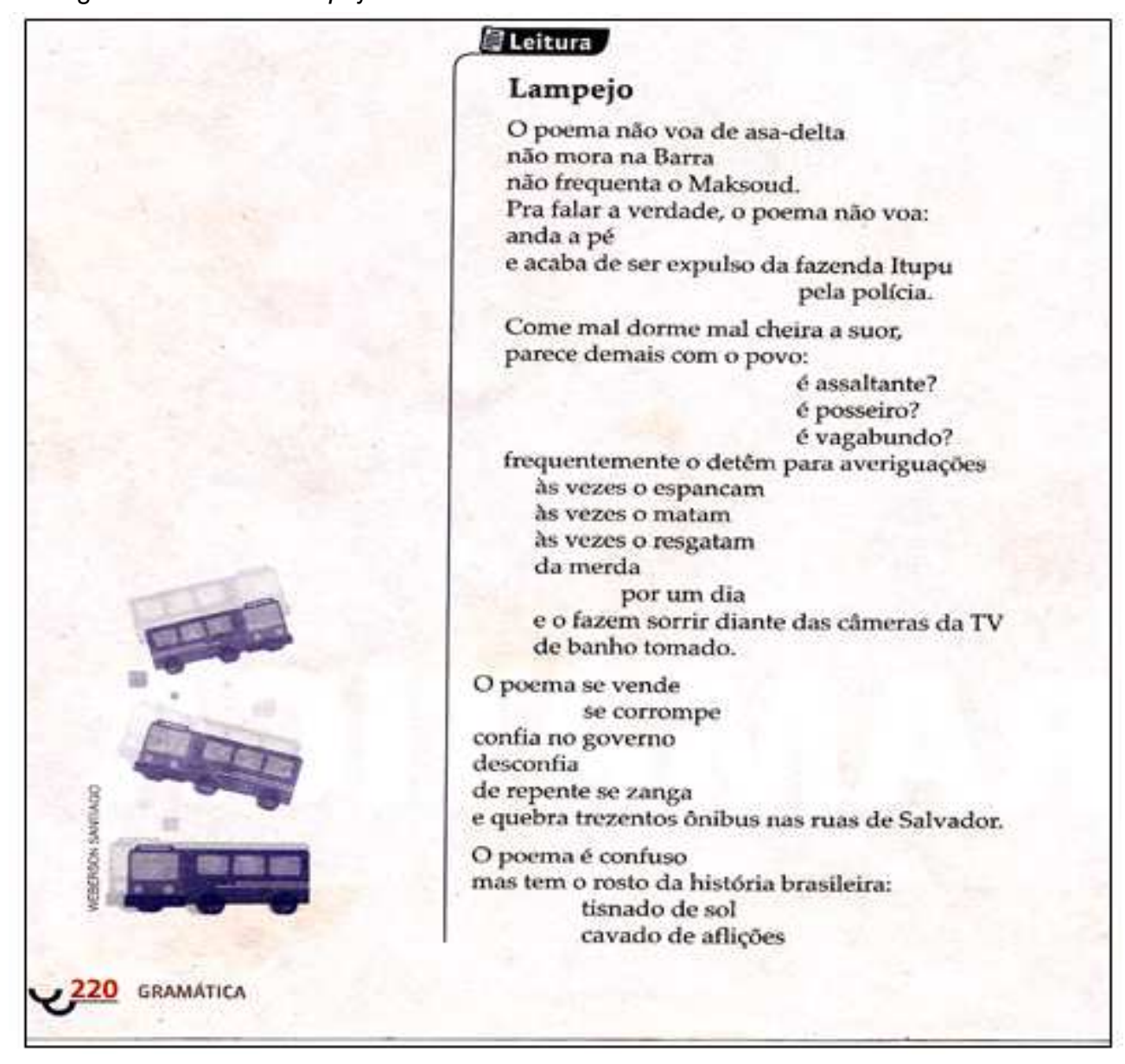

Fonte: (SARMENTO; TUFANO, 2010, p.221.)

Assim, temos um gênero literário constituído por metáforas para representar um dos aspectos da realidade social que é a desigualdade consonante aos modos de viver o dia a dia. Diante disso, é importante enfatizar que o texto literário verbal se configura como um gênero discursivo, e sua materialidade conta com os recursos linguísticos lexicais, fraseológicos e gramaticais que ao serem combinados possibilitam ao produtor textual transmitir a mensagem que se deseja. No caso específico do poema, objetiva-se emocionar, provocar liricamente o interlocutor mediado pelo texto que se constitui como um dos modos de manifestação da arte.

Tendo como princípio a oração como unidade da língua e suscetível a tornar-se enunciado pleno quando possibilita atitude responsiva por parte dos interlocutores numa situação comunicativa, apontamos que o poema Lampejo que abre o capítulo 8 do manual em estudo está configurado neste contexto como unidade da língua, pois serve como pretexto para sinalizar a composição linguística, formada principalmente por períodos compostos por coordenação e, em sua maioria, orações coordenadas assindéticas. Reconhecemos a importância em conhecer as particularidades que envolvem o processo de coordenação e subordinação na formação dos períodos compostos, sem se

Figura 2 - Poema Lampejo

e no fundo do olhar, no mais fundo, detrás de todo o amargor,

guarda um lampejo

um diamante

duro como um homem

e é isso que obriga o exército a se manter de prontidão.

GULLAR, Ferreira. Toda poesia. Rio de Janeiro: José Olympio, 2001. p. 356-357.
Lampejo: clarāo ou brilho momentâneo; faisca, centelha; inspiração súbita. restringir à mera identificação dessa ocorrência. Portanto, isso implica ir além do que é meramente sintático, atentando principalmente para os aspectos estilísticos 
que concorrem para as configurações semânticas, a fim de compreender a relevância e funcionalidade das formas para a construção do sentido do texto como um todo.

Desse modo, verificamos que os versos apresentados por orações coordenadas assindéticas e outros, com menor ocorrência, por orações coordenadas aditivas ou adversativas possibilitam perceber no poema, com as metáforas utilizadas, uma denúncia sobre as desigualdades sociais sofridas por aqueles que vivem à margem da sociedade. E se tomamos o sentido de lampejo, ele encerra, no caos que caracteriza o estar no mundo, a representação e a expressão do eu-lírico.

De acordo com Garcia (2006), mesmo que as orações coordenadas sejam consideradas como independentes, elas podem, em certos momentos, ser subordinadas quanto aos aspectos semânticos. Nesse sentido, o que ocorre é a existência de "dependência semântica mais do que sintática" (GARCIA, 2006, p.47). Ele considera que para serem verdadeiramente independentes, as orações precisam não apenas da autonomia de função, mas também de sentido.

Uma proposta linguístico-pedagógica que considera as relações dialógicas poderá conduzir o aluno a perceber e refletir acerca dos fins estéticos utilizados no poema. Portanto, deve ser discutido desde a apresentação visual, na qual se estruturam os versos e estrofes bem como a mensagem comunicada, atentando-se ao fato de que no poema, a linguagem representa um dos recursos que fazem com que as estratégias de escrita possam ir além da mera função de informar.

É nesse ponto que se torna relevante destacar a importância da escolha do tipo de período mais adequado na produção de determinado gênero, aliado aos objetivos pretendidos pelo produtor dele, pois, só assim seria possível perceber que as escolhas lexicais, morfossintáticas e semânticas possibilitam ao produtor de texto ter ou não êxito ao escrever, porque cada vez que se escreve, o objeto desse processo de produção é passível de múltiplos sentidos que serão construídos por todos aqueles envolvidos no processo da recepção.

Assim, o entendimento sobre a construção dos múltiplos sentidos a serem suscitados por meio dos diferentes modos de elaborar os períodos compostos permite ao aluno se constituir e se ver como autor, pois será semântica e estilisticamente que se dará o tom das reflexões acerca da sintaxe das orações. Tal fato nos aponta para o que Bakhtin (2013) afirma:

Toda forma gramatical é, ao mesmo tempo, um meio de representação. Por isso, todas essas formas podem e devem ser analisadas do ponto de vista das suas possibilidades de representação e de expressão, isto é, esclarecidas e avaliadas de uma perspectiva estilística. (BAKHTIN, 2013, p.24)

A reflexão que propomos neste artigo não pretende invalidar a importância dos fatos linguísticos à luz das gramáticas, mas, ao problematizar as discussões sobre eles, contribuir com os estudos linguísticos contemporâneos sob as diversas vertentes teóricas em que a perspectiva dialógica do discurso - de Bakhtin e o Círculo - nos fundamentam.

Apresentamos, a seguir, definições contempladas no Livro Didático Português: literatura, gramática, produção de texto sobre os processos da coordenação e subordinação e que sugerem ao aluno que apenas o modo como as orações são classificadas pode ser o suficiente para estabelecer as relações de dependência ou não entre elas. Portanto, nem as conceituações e nem as atividades abordam questionamentos para constatar se os sentidos provocados pelas orações coordenadas são realmente independentes sintaticamente ou não.

Figura 3 - Conceitos - oração/ período

Período simples é aquele constituido de uma só oração. Periodo composto é o que apresenta duas ou mais orações.

Periodo composto por coordenação é aquele formado por oraçōes independentes, que se chamam oraçōes coordenadas.

Oraçăo coordenada assindética é aquela que não tem conjunção, e é justaposta à outra oração ou separada dela por vírgula.

Oração coordenada sindética é a que tem conjunção coordenativa que a liga a outra oração.

Fonte: (SARMENTO e TUFANO, 2010, p.222.)

Notamos que o texto utilizado para exemplificar as considerações iniciais sobre período simples e 
período composto explora os aspectos gramaticais centrados basicamente na forma, consequentemente, a abordagem daí empreendida fica restrita ao caráter puramente estrutural no que concerne ao tema em estudo. Retomando o que Bakhtin afirma, é preciso reconhecer que:

Sem a abordagem estilística, o estudo da sintaxe não enriquece a linguagem dos alunos e, privado de qualquer tipo de significado criativo, não Ihes ajuda a criar uma linguagem própria; ele os ensina apenas a analisar a linguagem alheia já criada e pronta. Entretanto, isso já é escolástico (BAKHTIN, 2013, p.28).

Agora, observemos a figura 4, a seguir.

Figura 4 - Atividade sobre o poema Lampejo

e no fundo do olhar, no mais fundo, detrás de todo o amargor,

guarda um lampejo

um diamante

duro como um homem

e é isso que obriga o exército a se manter de prontidão.

GULLAR, Ferreira. Toda poesia. Rio de Janeiro: José Olympio, 2001. p. 356-357.

1 A função do poeta pode diferir, de acordo com a sua criação poética.

a) Que função apresenta o poema de Gullar, tendo em vista o conteúdo?

b) Segundo o texto, pode-se dizer que a poesia de Gullar tem pretensões elitistas? Esclareça sua resposta.

c) 0 póma apresenta uma linguagem por vezes irreverente. Por que 0 autor pode ter optado por esse tipo de linguagem?

2 Observe a construção das estrofes $c$ dos versos no poema.

- Que características comprovam certa preocupação experimental na organização do texto?

3 Por que o povo, mesmo quando representado por cidadãos honestos, é muitas vezes confundido com marginais, em situações de protesto? 0 que você pensa disso?

- Você consegue transpor essa situação descrita no poema para a sua realidade?

4 Nos últimos versos, o eu lírico se mostra esperançoso em relação ao povo brasileiro.

- 0 que lhe dá a certeza de que o povo também mantém a confiança no futuro?

5 Releia estes versos, como se estivessem pontuados no texto.

- O poema não voa de asa-delta.

Não mora na Barra.

Não frequenta o Maksoud.

E agora, com outro tipo de pontuação.

- "O poema não voa de asa-delta

não mora na Barra não frequenta o Maksoud."

a) Nos dois textos, as orações são independentes (têm sentido completo) ou dependentes (têm sentido incompleto)?

b) Em cada texto, quantos são os períodos e como se chamam? Esclareça sua resposta.

6 As orações que são independentes e não têm conjunção, vêm justapostas ou separadas por vírgula, são chamadas orações coordenadas assindéticas.

- Quais são as orações coordenadas assindéticas do período composto do segundo texto?
Fonte: (SARMENTO e TUFANO, 2010, p.221.)

Conforme podemos observar na Figura 4, os

exercícios de interpretação textual revelam uma categorização entre compreender os possíveis sentidos e reflexões implícitos no texto, como se pode observar nas questões 1 (a, b, c), 3 e 4, bem como a organização estrutural do texto condicionada pelos versos e rimas que são pontuados na questão 2. Em se tratando da questão 5, sugere perceber as relações de in/dependência das orações com foco na postulação do conceito e não em análises dos possíveis efeitos de sentido que tais orações implicam ao texto como um todo discursivo. Assim, o que se evidencia é a segregação do estudo da compreensão do texto, de um lado e, por outro, a abordagem de exercícios sobre conceitos e classificações dos períodos compostos.

Nesse sentido, as informações sobre o processo de coordenação se pautam apenas em conceituar as orações como independentes, sem que haja uma preocupação em discorrer sobre as relações entre elas para a construção dos efeitos de sentido que um ou outro período pode ter quando possui conjunção ou não. Esse fato pode comprometer a aprendizagem do aluno no que diz respeito ao conhecimento gramatical com fins estilísticos, pois, como aponta Costa Val (2002, p.118): "antes da conceituação e da análise gramatical, os recursos linguísticos cujo emprego e compreensão se quer ensinar devem ser motivo de utilização intencional, observação deliberada, reflexão pessoal e interessada, descoberta por parte dos alunos". 
As descrições sobre o processo de coordenação apresentadas por Garcia (2006) nos levam a entender que não basta apenas aceitar que toda oração coordenada implica em independência de sentido, como se a sentença por si só já fosse o bastante para entender o sentido de um enunciado como um todo. Ao invés de afirmar que elas estabelecem relação de independência, ele enfatiza a existência de paralelismo sintático que pressupõe um encadeamento de ideias:

$\mathrm{Na}$ coordenação (também dita parataxe), que é um paralelismo de funções ou valores sintáticos idênticos, as orações que se dizem da mesma natureza (ou categoria) e função, devem ter a mesma estrutura sintáticogramatical (estrutura interna) e se interligam por meio de conectivos chamados conjunções coordenativas. $\mathrm{E}$, em essência, um processo de encadeamento de ideias. (GARCIA, 2006, p.42)

Podemos constatar que de acordo com as proposições de Garcia (2006), a coordenação estabelece uma equivalência sintática entre as orações, todavia, a autonomia de sentido é questionável, pois, se trata de uma correlação entre ideias, sendo assim, embora sejam conceituadas como independentes, haverá a dependência de sentido.

Vale salientar que cada vez que o aluno se deparar com o estudo da sintaxe dos períodos simples e compostos com vistas a uma abordagem dialógica da linguagem, ele poderá entender o quanto Ihe é útil conhecer a funcionalidade dos tipos de orações, a fim de poder empregá-las de maneira estratégica ao produzir texto de gêneros diversos. Portanto, é pertinente estarmos atentos ao que Bakhtin defende quanto aos períodos compostos sem ou com conjunção:

É muito importante fazer com que os alunos escutem e avaliem aqueles momentos de expressividade (sobretudo emocional) que desaparecerão quando a construção sem conjunção for transformada em um período composto com conjunção; eles devem sentir o papel norteador exercido pela entonação nos períodos desse tipo; eles devem sentir e ver qual a necessidade interna de combinar a entonação com a mímica e o gesto [...]. (BAKHTIN, 2013, p. 30.)

Como temos visto, nas proposições já apresentadas anteriormente e que descrevem de forma breve a natureza do enunciado e seus tipos relativamente estáveis que são os gêneros discursivos, o gênero é organizado pela forma, todavia, a opção estilística por uma forma gramatical ou outra depende do tipo do gênero discursivo que se deseja produzir, porque ele se configura de acordo com a esfera na qual se insere. Portanto, "os gêneros do discurso organizam o nosso discurso quase da mesma forma que o organizam as formas gramaticais (sintáticas)" (BAKHTIN, 2016, p. 39).

\section{A subordinação - dialogismo e expressão na divulgação científica}

Entendemos com Bakhtin (2013) que a competência linguística do usuário da língua está para além da frase, já que só com os gêneros é que se estabelecem as relações discursivas. Portanto, estudar, analisar esse ou aquele gênero vai além, também, de sua forma, pois o que os determina é "a multiforme atividade humana". Então, tomamos como premissa a seguinte pergunta: $O$ que é a Divulgação Científica? A DC (Divulgação Científica) pressupõe compreender a noção de esfera/campo defendidas por Bakhtin e Bourdieu. Sendo assim, vale pontuar as proposições apresentadas por Grillo (2013) em sua tese de livre-docência ao afirmar que

$\mathrm{Na}$ esfera educacional, ela está presente em gêneros como os livros e manuais didáticos, a aula (expositiva, seminário, estudo do texto etc.), livros paradidáticos etc. Essa esfera é bastante heterogênea em razão do nível de ensino, mas seus elementos comungam o fato de que os destinatários presumidos formam um público cativo e que a aprendizagem tem um caráter sistemático, visando à aprendizagem de conceitos. (GRILLO,2013, pag.94)

Os textos da DC presentes no manual didático são exemplos dos quais os alunos terão contato na leitura e na escrita no seu fazer diário. A leitura desses gêneros nos indicia que no processo de construção sintática dos períodos opta-se por esse ou aquele recurso visando conferir verdade e certa fidelidade ao dito por outrem. Sendo assim, observemos, na Figura 5, como um texto retirado da revista Galileu é apropriado pelo livro didático e a finalidade de seu uso: 


\section{Geitura}

\section{$\mathrm{O}$ que causa as eras de gelo?}

Quando o filme $\mathrm{O}$ dia depois de amanhã foi lançado, em 2004, muita gente entrou em desespero. Pipocaram na imprensa e entre amigos discussōes sobre a situação apresentada: o mundo sendo tomado por gelo, e tudo por causa do aquecimento global. Aquilo poderia mesmo acontecer? Em quanto tempo?

$\mathrm{O}$ que os cientistas sabem hoje é que eras de gelo de pequena escala ocorrem a cada 20 mil ou $40 \mathrm{mil}$ anos, e que eras mais duradouras acontecem a cada 100 mil anos ou mais. O que falta saber é o porquê.

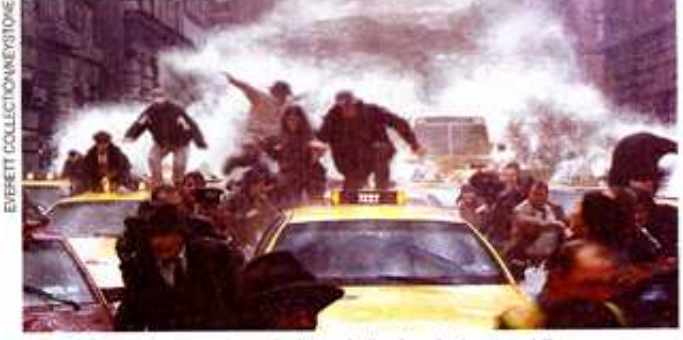

Cena da filme o dla depois de amanhớ. direçă de Roland Emmerich. EUA, 2004
Atualmente, os pesquisadores se debrucam sobre uma teoria, pensada inicialmente em 1920, que diz que irregularidades na órbita da Terra mudam o quanto de energia solar o planeta absorve, resultando em aquecimentos repentinos. Partindo dela, foram atrás de estudar o quanto essas flutuaçōes orbitais afetam a energia solar. $\mathrm{O}$ resultado? Apenas $1 \%$ de influência, porcentagem insuficiente para gerar alguma variaçāo climática. A nova dúvida dos pesquisadores, então, é qual o fator que leva uma pequena quantidade de energia solar a produzir uma glaciação em larga escala.

Estudos do gelo e de cores do solo oceânico mostram que a variação de temperatura tem profunda ligação com a concentração de gases do efeito estufa. Mas não se sabe se a variação no nível de $\mathrm{CO}$ causa a mudança no clima ou se é apenas efeito dessa mudança. $\mathrm{E}$ a tal da história sobre quem veio primeiro, o ovo ou a galinha. Os geólogos acreditam que descobrir isso pode abrir novos caminhos para enfrentar o problema do aquecimento global, e o ponto de partida, segundo o geólogo Matthew Saltzman, é descobrir por que os gases do efeito estufa oscilavam em tempos pré-hístóricos.

$$
\text { Galiteu, São Paulo, p. 38, } 1^{\text {a }} \text { dez, } 2007 \text {, }
$$

ao mesmo tempo

é também 0 discurso sobre o discurso, $\quad 0$ enunciado sobre o enunciado" (BAKHTIN, 2017, p.249) e configurado na forma do discurso indireto, em que o divulgador científico revista Galileu) responde ao público (os nãoespecialistas) se o que é mostrado no filme é

possível

Fonte: (SARMENTO e TUFANO, 2010, p.231.)

Podemos afirmar que o texto inicia utilizandose do discurso direto - uma pergunta: "O que causa as eras de gelo?" (SARMENTO E TUFANO, 2010, p.231) e a seguir vem a resposta em que é utilizado o discurso indireto livre. $\mathrm{E}$, nessa resposta, ecoam as vozes da ciência, com predomínio dos períodos compostos por coordenação sindética e/ou subordinação.

Nesse texto encontramos o discurso da ciência, embora não seja um texto científico, que objetiva apresentar, de forma clara e direta, as consequências do aquecimento global. Para tanto, inicia-se comentando o impacto provocado pelo filme "O dia depois de amanhã" que retrata os nefastos efeitos do aquecimento global. Assim, com intuito de estabelecer um paralelo entre a realidade fictícia retratada no filme e a possibilidade de que o mesmo aconteça na vida real, recorre-se ao discurso direto: "Aquilo poderia mesmo acontecer"? "Em quanto tempo"?

A resposta é apresentada na forma de discurso citado da ciência, "o discurso alheio é o discurso acontecer na vida real. É assim que o artigo, como um gênero jornalístico da esfera da DC, através do discurso indireto, mostra ao interlocutor o que a ciência diz sobre $o$ aquecimento global $e$ as consequências para a vida no planeta. Nesse sentido, o divulgador científico, ao evidenciar que apenas fala por um outro, se isenta da responsabilidade sobre a informação transmitida a um outro, por isso enfatiza: "os cientistas sabem"; "os pesquisadores se debruçam sobre a teoria".

A composição do texto "O que causa as eras de gelo?" conta com os recursos estilísticos e sintáticos característicos do gênero pelo qual se configura. Assim, para materializar o discurso da ciência numa linguagem cotidiana e habitual, dentre outras estratégias linguísticas, notamos que a ocorrência dos períodos compostos por subordinação tem maior incidência. Desse modo, ao longo do texto, vemos as orações subordinadas estabelecendo relações de dependência semântica e sintática em torno de uma oração principal, atendendo à necessidade do produtor do texto de mostrar de forma mais detalhada cada uma das afirmações que 
se predispôs a apresentar. Selecionamos do texto em análise dois períodos que tratam especificamente do assunto: primeiro período: "O que os cientistas sabem hoje é que eras de gelo de pequena escala ocorrem a cada 20 mil ou 40 mil anos"[...]; segundo período: "Estudos do gelo e de cores do solo oceânico mostram que a variação de temperatura tem profunda ligação com a concentração de gases do efeito estufa".

No primeiro período, a oração principal reforça a característica da esfera a qual pertence o gênero em estudo e põe em segundo plano a questão central do texto, apontada desde o título. Essa construção está estruturada como um período composto por subordinação, em que a segunda oração é uma subordinada substantiva que exerce a função de objeto direto da oração principal. Como já havíamos pontuado anteriormente, essa construção sintática em que os termos estabelecem relação de dependência entre si e servem justamente para ressaltar o discurso indireto e eximir o divulgador científico da responsabilidade do conteúdo apresentado demonstra que há um eu falando pelo outro e para o outro.

No segundo período selecionado, o tema abordado é apresentado na oração principal, acentuando a relevância da informação ali divulgada. Aqui, se trata também de um período composto por subordinação, em que a oração subordinada é uma objetiva direta. O teor dessa informação científica só terá validade nesse período quando ela for vinculada ao texto como um todo. A estratégia discursiva utilizada nessa construção visa responder à perguntatítulo, ou seja, saber se por conta do aquecimento global poderá o mundo ser inundado, como aconteceu no filme citado no texto.
De todo modo, podemos verificar que nos dois períodos não existe uma hierarquia de sentido postulado entre as orações principais $e$ as subordinadas, isso porque a compreensão das informações só será possível se buscar o sentido na totalidade dos períodos e não nas partes isoladas. Por isso, faz-se necessário conhecer o funcionamento das formas para selecionar adequadamente aquelas que atenderão melhor à intenção discursiva do produtor de texto.

Limitamo-nos, aqui, em fazer uma análise simplificada da relação dos processos sintáticos dos períodos compostos, em um livro didático, considerando o que caracteriza o gênero em que esse texto se insere, pois o nosso objetivo não consiste em explorar de modo mais minucioso todas as particularidades que podem ser suscitadas com a construção dos períodos selecionados. No entanto, cremos que atendemos ao propósito de mostrar como a escolha estilística por um determinado período implica na constituição do sentido de um gênero discursivo como um todo. De igual modo, mostraremos, em um outro texto de DC, outras implicações ao sentido proporcionado pelo processo de subordinação do período composto. Observemos a Figura 6:

Figura 6 - Carboidratos e regime não combinam

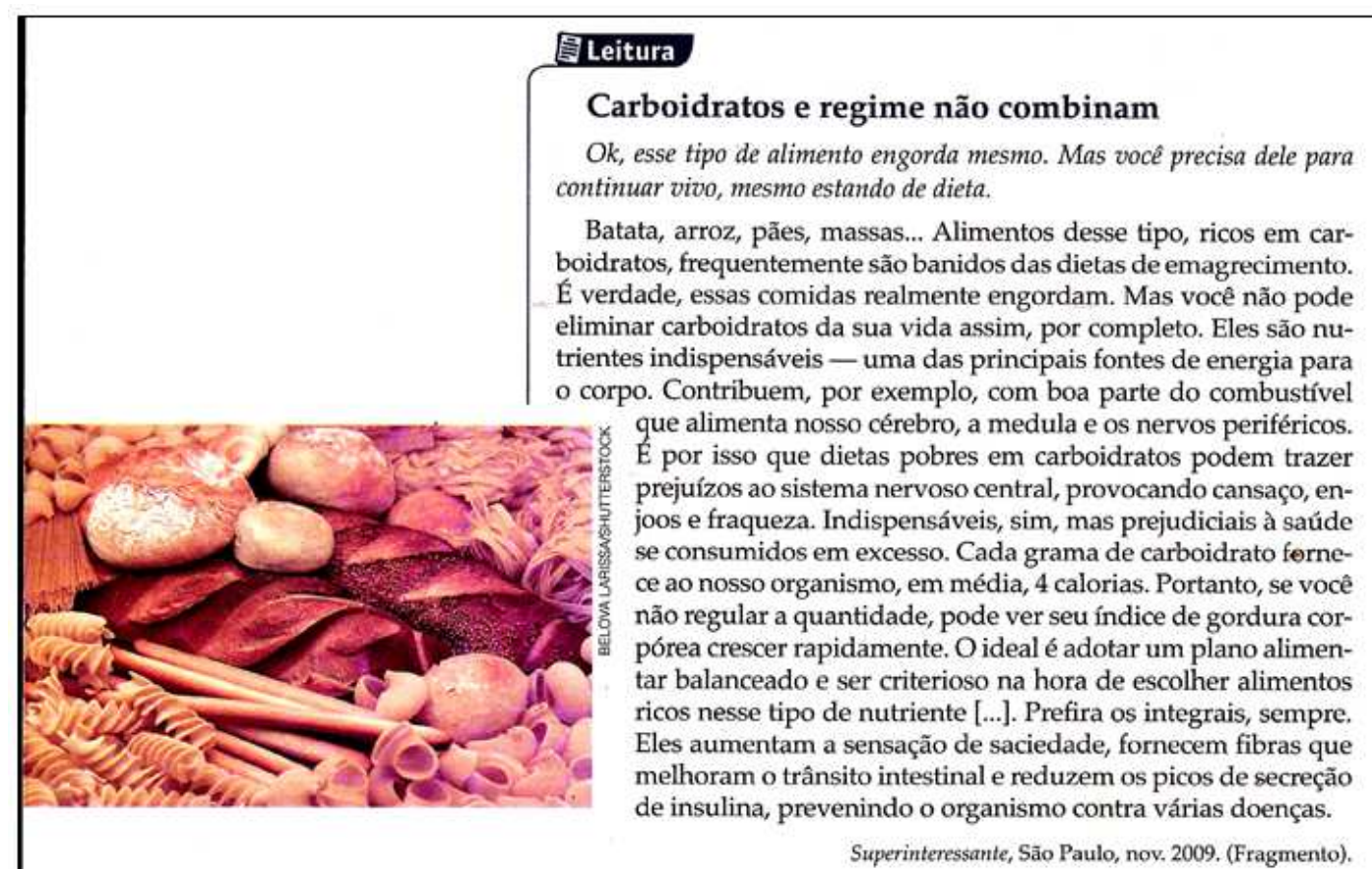

Fonte: (SARMENTO e TUFANO, 2010, p.236.) 
O texto "Carboidratos e regime não combinam" (SARMENTO; TUFANO, 2010, p.236), reportagem divulgada na revista Superinteressante, provavelmente, terá como interlocutor principal os indivíduos que se preocupam em manter uma dieta saudável, o que não pressupõe que o texto se restrinja apenas a esse público. No entanto, será preocupação de quem produz um determinado gênero discursivo adequar suas estratégias estilísticas ao público e à esfera de circulação de tal gênero.

Assim, mais uma vez, temos por premissa que

Quando escolhemos um determinado tipo de oração, não o fazemos por considerarmos 0 que queremos exprimir com determinada oração; escolhemos um tipo de oração do ponto de vista do enunciado por inteiro que se apresenta à nossa imaginação discursiva e determina nossa escolha." (BAKHTIN, 2016, p. 43).

Diante dessas proposições, lançamos nosso olhar para o texto já mencionado anteriormente, buscando entender as funcionalidades e possíveis intenções discursivas das orações subordinadas que o constituem. Para tanto, analisaremos os seguintes períodos:

Primeiro período: "É verdade, essas comidas realmente engordam".

Segundo período: É por isso que dietas pobres em carboidratos podem trazer prejuízos ao sistema nervoso central [...]

Como pode ser percebido no texto da Figura 6 , dentre outros recursos linguísticos, há nesse texto predominância das orações subordinadas em relação às coordenadas, o que se configura como a opção estilística do autor, por corresponder às suas pretensões discursivas nesse contexto. Temos, portanto, no primeiro período selecionado uma oração subordinada substantiva completiva nominal. Vejamos a importância desse período no contexto em que se insere: no título está posto que carboidratos e regime não combinam, nesse sentido, o período que destacamos possui estrita relação semântica, pois atua como uma justificativa para 0 que foi apresentado no título, reafirmando que carboidratos não combinam com regime porque faz engordar.

Notamos que os sentidos de cada oração estão implicados entre si e consequentemente no texto por inteiro. E por que dizemos que é uma completiva nominal? Ela é assim conceituada por completar o sentido do verbo "ser" que não corresponde a uma ação, mas sim a uma condição ou estado. Conforme Garcia (2006, p.66), "na oração principal deve estar a ideia predominante do período, segundo a intenção do autor, segundo o ponto de vista em que ele, e não o leitor, se coloca". Entretanto, ao considerar "é verdade" como a oração principal e "essas comidas realmente engordam", fica evidente que, para compreender o sentido, deve-se buscar essa compreensão na oração subordinada e não na oração principal, como costuma ocorrer, pois "em certos casos, é verdade, a oração subordinada constitui condição ou circunstância indispensável à eficácia comunicativa" (GARCIA, 2006, p. 65).

No contexto discursivo em que se insere, 0 segundo período selecionado funciona como uma ressalva em relação ao pressuposto de que carboidrato não é tão ruim, como sugere o título do texto. A oração subordinada mostra uma importante divulgação do conhecimento científico que é o esclarecimento sobre as possíveis consequências da carência de carboidratos no organismo humano.

O discurso da ciência, reproduzido na Figura 6, de Divulgação Científica, do gênero reportagem, mistura-se à linguagem cotidiana através da estratégia estilística de reunir os conhecimentos sobre carboidratos numa criteriosa seleção de orações predominantemente subordinadas. Desse modo, não se percebe na reportagem "a transposição palavra por palavra, por procedimentos puramente gramaticais, de um esquema para outro, sem fazer as modificações estilísticas correspondentes" (BAKHTIN, 2017, p. 268). De tal modo, ao falar pelo outro e para um outro, utilizando-se do discurso indireto, o divulgador científico traz para $\mathrm{si}$, sintaticamente falando, a responsabilidade do que é divulgado.

Em face das proposições desenvolvidas sobre o processo dos períodos compostos nos gêneros 
selecionados, queremos destacar a complexidade que há nas escolhas estilísticas e, para isso, recorremos ao que Garcia (2006) estabelece sobre a constituição dos períodos compostos:

\begin{abstract}
A organização sintática de um período complexo não é tarefa gratuita. A articulação das orações (ou enunciados) exige faculdade de análise, de discriminação, de raciocínio lógico, enfim. $O$ autor deve ter presente ao espírito a concorrência de fatores e elementos diversos (termos, agrupamentos de termos, orações, ordem de uns e outras, grau de relevância das ideias segundo o ponto de vista, etc.) Deve procurar dar a cada um desses elementos e fatores, assim como ao seu conjunto, uma estrutura e disposição que estejam de acordo não apenas com as normas sintáticas mas também com a hierarquia entre eles, combinando-os de maneira que expressem o pensamento com necessária clareza, objetividade, precisão e relevo. (GARCIA, 2006, p.71)
\end{abstract}

Desse modo, por meio das articulações de períodos sintáticos complexos que atendem às necessidades estilísticas, a Divulgação Científica divulga e dissemina as informações que poderiam ficar restritas apenas aos que estão envolvidos no campo da ciência ou aos que aspiram ao fazer científico, por isso, passam a ser do conhecimento de todos aqueles que buscam estar bem informados acerca dos avanços tecnológicos e científicos. Contudo, quando pensamos em DC, faz-se necessário pensar também nos aspectos que englobam desde a produção do conhecimento científico aos que dizem respeito tanto à transmissão quanto à recepção.

Portanto, é importante afirmar que os conhecimentos científicos e tecnológicos dialogam com outras esferas, no entanto, vale destacar que tal diálogo vai além da preocupação com os aspectos terminológicos em que ocorre a substituição de um termo por outro, "mas coloca em contato diferentes esferas de produção de saberes, compostas por centros valorativos próprios, por seus gêneros, por suas imagens" (GRILLO, 2008, p.69) e, a partir de então, esses conhecimentos passam pelo crivo avaliativo dos sujeitos que, apesar de leigos, tiveram acesso às informações dessas produções científicas.

\section{Considerações Finais}

Intencionamos mostrar, mediante as descrições da análise de determinados textos contidos no livro didático Português - Literatura, gramática, produção de texto (SARMENTO; LAUAR, 2010), que o tratamento sobre a sintaxe dos períodos compostos refere-se às construções linguísticas denominadas de orações, configurada como unidades convencionais da língua. No entanto, entendemos que as atividades realizadas no livro não contemplam discussões sobre a constituição da linguagem como fruto das relações dialógicas entre os indivíduos. Assim, grande parte do trabalho referente a esse assunto no material estudado está limitada a classificar as orações, mostrar o funcionamento delas, utilizando-se de textos de gêneros diversos. Embora, em alguns momentos, sejam pontuadas questões relacionadas à construção de sentido, de um modo geral, a abordagem feita não explora a importância das escolhas estilísticas por determinado período simples ou composto para indiciar os múltiplos sentidos para os envolvidos na interação verbal. Por isso, enfatizamos a relevância da abordagem dialógica sobre a sintaxe das orações, de forma tal que seja possível refletir sobre a constituição do enunciado como parte das ações humanas realizadas e considerando as múltiplas vozes existentes na produção deles.

À medida que analisamos o livro didático, objetivamos discutir a relevância que há em estudar a sintaxe dos períodos compostos, considerando o contexto do gênero discursivo no qual está inserida. Para tanto, tentamos mostrar, através de alguns gêneros da Divulgação Científica bem como de um gênero literário (poema), os possíveis efeitos de sentido implicados ao realizar uma escolha estilística por um ou outro período composto. Os textos da Divulgação Científica, dentre outras especificidades, são pertinentes ao proporcionar aos que não possuem o domínio dos conhecimentos científicos a possibilidade de realizar leituras mais simplificadas e 
de fácil compreensão, pois o conteúdo divulgado na DC, ao invés de se restringir à linguagem científica, recorre àquela que é mais comum entre os usuários da língua. De igual modo, o poema, enquanto fenômeno de comunicação cultural, que faz uso dos mais diferentes recursos denotativos da linguagem, cuja finalidade não consiste em apresentar apenas a literalidade da língua, também necessita ser fruto de escolhas bem planejadas no que tange ao uso de períodos compostos. Apesar disso, só poderá ser melhor compreendido se estiver em estrita relação com as situações que propiciaram a sua produção. Portanto, um dado gênero discursivo pode determinar a escolha entre uma oração coordenada ou subordinada.

Assim, evidenciamos que é possível realizar um ensino dos aspectos gramaticais numa perspectiva dialógica da linguagem. Aqui, restringimonos a mostrar apenas discussões concernentes ao processo dos períodos compostos por coordenação e subordinação. Reconhecemos que não é tarefa fácil aliar os aspectos gramaticais aos dialógicos, entretanto pode se tornar uma abordagem de ensino e aprendizagem mais significativa para o aluno, à medida que ele tenha oportunidade para refletir sobre os efeitos de sentido proporcionados pelas construções sintáticas. Portanto, defendemos que mais importante do que saber classificar e nomear os diferentes tipos de oração é compreender que elas precisam estar vinculadas às reais situações enunciativas, reconhecendo que são consequências das escolhas estilísticas de um determinado sujeito do discurso.

\section{Referências}

BAKHTIN, Mikhail Mikhailovich. Questões de estilística no ensino da língua. São Paulo: Editora 34, 2013. $176 \mathrm{p}$.

Os gêneros do discurso. Paulo Bezerra (Organização, tradução, posfácio e

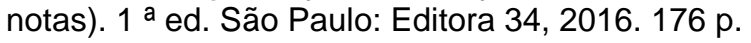

(V.N. Volochínov). Marxismo e Filosofia da Linguagem - Problemas fundamentais do Método Sociológico na Ciência da Linguagem. Sheila Grillo; Ekaterina Vólkova Américo (Tradução, notas e glossário). São Paulo: Editora 34,2017. 376 p.

BRAIT, Beth. Estilo. In:

Bakhtin: Conceitos-Chave. 5a. ed. São Paulo: Contexto, 2013. 79-102 p.

COSTA VAL, Maria da Graça. A gramática do texto, no texto. v.10, n. 2. Belo Horizonte: Revista de Estudos da Linguagem, 2002. p.107-133. Disponível em: http://periodicos.letras.ufmg.br. Acesso em 20 de dezembro de 2018.

GARCIA, Othon Moacyr. Comunicação em prosa moderna. 26a . ed. Rio de Janeiro: FGV, 2006. 540p.

GRILLO, Sheila Vieira de Carvalho. Divulgação científica: linguagens, esferas e gêneros. 2013. 333f. Dissertação. Sheila Vieira de Carvalho Grillo (Orientador). Livre- Docência - Faculdade de Filosofia, Letras e Ciências Humanas da Universidade de São Paulo, 2013.

SARMENTO, Leila Lauar; TUFANO, Douglas. Português - Literatura, Gramática e Produção de Texto. 1. ed. São Paulo: Moderna, 2010. 416 p.

SOBRAL, Adail. Do dialogismo ao gênero: as bases do pensamento do Círculo de Bakhtin. Séries ideias sobre linguagem. Campinas, SP: Mercado de Letras, 2009. 175 p.

\section{COMO CITAR ESSE ARTIGO}

PAIXÃO, Ediram de Souza; TORGA, Vânia Lúcia Menezes. Processo de coordenação e subordinação em um livro didático - um estudo à luz de bakhtin e o círculo. Signo, Santa Cruz do Sul, v. 44, n. 80, p. 206-218, ago. 2019. ISSN 1982-2014. Disponível em: <https://online.unisc.br/seer/index.php/signo/article/view/13263>. Acesso em: doi: https://doi.org/10.17058/signo.v44i80.13263. 